\title{
The fate of human Langerhans cells in hematopoietic stem cell transplantation
}

\author{
Matthew P. Collin, ${ }^{1}$ Derek N.J. Hart, ${ }^{2}$ Graham H. Jackson, ${ }^{1}$ Gordon Cook, ${ }^{3}$ \\ James Cavet, ${ }^{4}$ Stephen Mackinnon, ${ }^{5}$ Peter G. Middleton, ${ }^{1}$ \\ and Anne M. Dickinson ${ }^{1}$
}

${ }^{1}$ Haematological Sciences, University of Newcastle, Newcastle upon Tyne NE2 4HH, England, UK

${ }^{2}$ Mater Medical Research Institute, South Brisbane, Queensland 4101, Australia

${ }^{3}$ Department of Haematology, St. James's University Hospital, Leeds LS9 7TF, England, UK

${ }^{4}$ Department of Haematology, Christie Hospital NHS Trust, Manchester M2O 4BX, England, UK

${ }^{5}$ Department of Haematology, Royal Free and University College London Medical School, London NW3 20G, England, UK

Langerhans cells (LC) and other antigen-presenting cells are believed to be critical in initiating graft versus host responses that influence the outcome of allogeneic hematopoietic stem cell transplantation. However, their fate in humans is poorly understood. We have sought to define the effect of conditioning regimes and graft versus host disease (GVHD) on the survival of recipient LC and reconstitution of donor cells after transplant. Confocal microscopy of epidermal sheets shows that full intensity transplant (FIT) depletes LC more rapidly than reduced intensity transplant (RIT) at day 0 , although the nadir is similar in both at 14-21 d. Recovery occurs rapidly within $40 \mathrm{~d}$ in the absence of acute GVHD, but is delayed beyond $100 \mathrm{~d}$ when GVHD is active. LC chimerism was determined in sexmismatched transplants using a two-step Giemsa/fluorescence in situ hybridization assay on isolated cells. Acquisition of donor chimerism at $\mathbf{4 0} \mathrm{d}$ is more rapid after FIT (97\%) than RIT (36.5\%), irrespective of blood myeloid engraftment. At $100 \mathrm{~d}$, all transplants achieve at least $90 \%$ LC donor chimerism and over half achieve 100\%. Complete donor chimerism is associated with prior acute cutaneous GVHD, suggesting a role for allogeneic T cells in promoting LC engraftment.

CORRESPONDENCE

Matthew Collin:

matthew.collin@ncl.ac.uk
Graft versus host disease (GVHD) is an immune reaction of donor lymphoid cells to antigens expressed by recipients of hematopoietic stem cell transplantation (HSCT). In the acute form, occurring within $100 \mathrm{~d}$ after transplant, GVHD is a significant cause of transplant-related mortality; as a chronic disease, occurring sometimes indefinitely from $100 \mathrm{~d}$ after transplant, it generates long-term morbidity (1).

In murine models, inactivation of recipient class I MHC prevents the initiation of acute GVHD (2) and selective class I MHC or costimulatory antigen knockout implicates both recipient and donor APCs in the full expression of chronic GVHD (3, 4). More specific analysis of cutaneous GVHD has revealed the potent function of recipient Langerhans cells (LC) and the attenuation of acute GVHD by temporal separation of donor engraftment in the LC and T cell compartments (5). The potential persistence of recipient LC after HSCT

$\overline{\text { The online version of this article contains supplemental material. }}$ has attracted renewed attention recently. Early studies showed partial LC engraftment (30-75\%) in murine radiation chimeras that were otherwise full donor chimeras of the blood and spleen (6). More recently, elegant work with parabiotic mice and $\mathrm{T}$ cell-depleted transplantation has demonstrated conclusively that LC renew locally in the epidermis during the steady state and only summon blood-borne precursors after injury $(5,7)$. Together, these results suggest that $\mathrm{LC}$ are important and distinct from other peripheral myeloid-derived cells in the biology of GVHD.

Recent reports of the effect of HSCT on human APC populations are limited to blood DCs. These show rapid donor repopulation in all transplants, in synchrony with blood myeloid cells (8-10). The fate of LC and other tissue-derived APCs, even though they are strongly implicated in murine GVHD, is much less well known in humans. After conventional full intensity transplantation (FIT), LC are depleted to a variable extent for weeks to months, but 
the relative contributions of conditioning therapy, cutaneous GVHD, and the treatment of GVHD are not clear (11-14). Targeted depletion of recipient APCs may be an attractive means to reduce acute GVHD, but better understanding of the effect of current conditioning regimens is required before this can be developed therapeutically.

Previous analysis of LC chimerism in humans is limited. In situ quinacrine Y-body analysis combined with OKT4 immunohistochemistry has demonstrated donor LC in a single female patient (15) and a subsequent study on a small cohort of male patients showed persistence of recipient LC in some patients (16). It is known that LC can proliferate locally in humans from EM studies (17) and the long-term maintenance of donor LC after human limb transplantation (18). With modern reduced intensity transplant (RIT), recipient LC survival after HSCT may be prolonged. This may delay the onset of acute GVHD after RIT (19) and increase the toxicity of early donor lymphocyte infusion (DLI) $(20,21)$. More generally, the transition from recipient to donor APCs has been thought to underlie the progression of clinical GVHD from acute to chronic $(22,23)$. This is an attractive theory, but has little experimental support in humans.

In this report, we describe in detail the effect of contemporary full and reduced intensity conditioning on human LC, their posttransplant reconstitution and chimerism. This provides new insights into their role in GVHD and potential as therapeutic targets.

\section{RESULTS AND DISCUSSION \\ The impact of conditioning on LC and potential of therapeutic depletion}

Skin biopsies were obtained pretransplant and on day 0 to assess the effect of RIT and FIT regimens on LC density. Intact epidermal sheets were examined by confocal microscopy as shown in Fig. 1 A. The natural arrangement of the LC network in the epidermal plane is readily appreciated from a collapsed Z-stack image. Enumeration was precise $(10.3 \%$ median variation between two $40 \times$ fields) and sensitive (minimum 5 LC per $\mathrm{mm}^{2}$ ). RIT had very little effect on LC density as illustrated by Fig. $1 \mathrm{~A}$; overall, there was a $9 \%$ downward trend from 644 to $588 \mathrm{LC} / \mathrm{mm}^{2}(\mathrm{P}=0.061$; Fig. $1 \mathrm{~B})$. FIT induced a $55 \%$ fall in LC from a median of 654 to $296 \mathrm{LC} / \mathrm{mm}^{2}$ ( $\mathrm{P}=0.001$; Fig. $1 \mathrm{~B}$ ), a significant drop but far from complete ablation of the population. Patients undergoing FIT were younger: median age was 34 (range: 20-54) compared with RIT, for which the median age was 43 (range: 21-57; $\mathrm{P}=0.020)$. Both had slightly reduced pretransplant counts compared with normal controls $\left(754 \mathrm{LC} / \mathrm{mm}^{2}\right)$, but this difference was not significant. There was no difference in day 0 counts with respect to alemtuzumab in conditioning regimens (not depicted), consistent with the observation that LC do not express CD52 (24, 25).

The hypothesis that recipient LC are essential in the afferent arm of acute GVHD is difficult to prove in humans without an interventional study (5). The retention of signif-
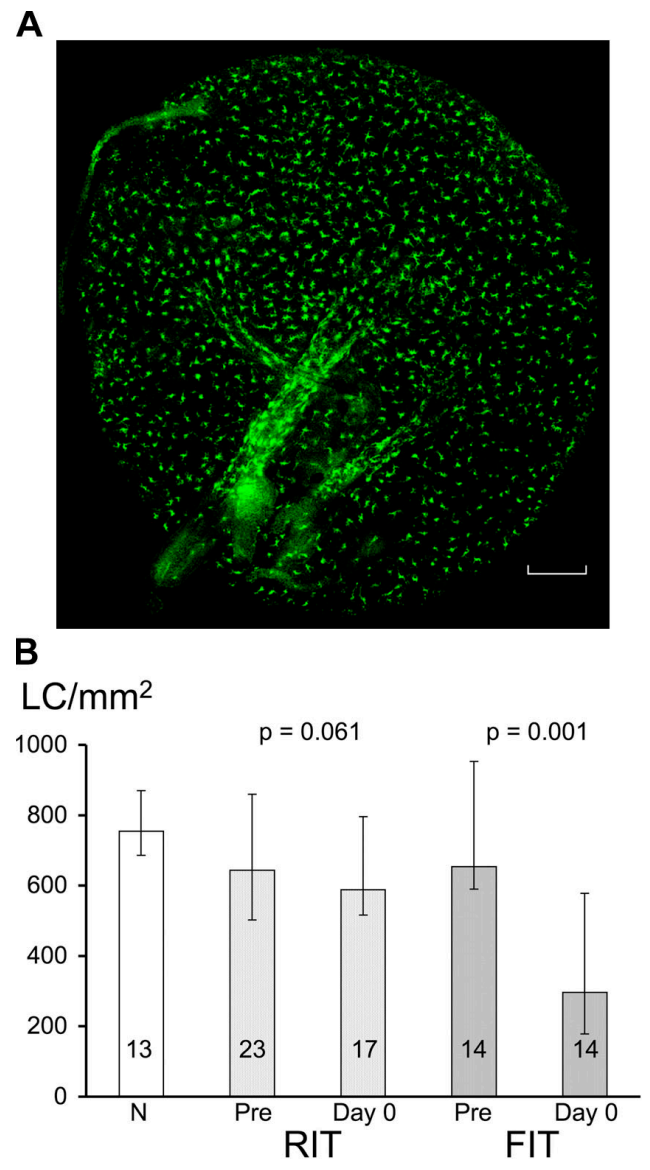

Figure 1. Effect of conditioning therapy on LC density. (A) Collapsed Z-stack confocal image of LC in the epidermis of a 2-mm punch biopsy on day 0 of RIT. Bar, $200 \mu \mathrm{m}$. The central structure is a hair follicle. (B) Comparison of conditioning regimens on LC density at day 0 . Median \pm interquartile range and sample number is shown. (white bar) $\mathrm{N}$, normal controls; (light gray bars) RIT, reduced intensity transplant; (dark gray bars) FIT, full intensity transplant. Pre, pretransplant (up to $14 \mathrm{~d}$ before the start of conditioning). Day 0, within $24 \mathrm{~h}$ of transplantation.

icant recipient LC on the day of transplantation is a necessary condition, but other APCs such as dermal DCs may also play a role in sensitizing donor lymphocytes in the draining lymph nodes. Although LC are depleted in GVHD (11-14), this reflects the efferent phase of GVHD (see next paragraph) and cannot be used as evidence of their role in GVHD induction.

Most LC survive RIT conditioning and, although cytokine activation may be diminished in RIT compared with FIT (1), the greater survival of recipient APCs may offset this benefit. Indeed, some non $\mathrm{T}$ cell-depleted RIT regimens have a delayed yet high cumulative incidence of acute GVHD, approaching that of conventional transplants $(19,26)$.

The prospect of attenuating acute GVHD by depleting recipient APCs was first suggested $>20 \mathrm{yr}$ ago (16). Our data imply that there is scope to accelerate or enhance LC depletion by novel conditioning therapies, such as UV light or monoclonal antibodies to DCs $(5,25)$. Others have argued 
A

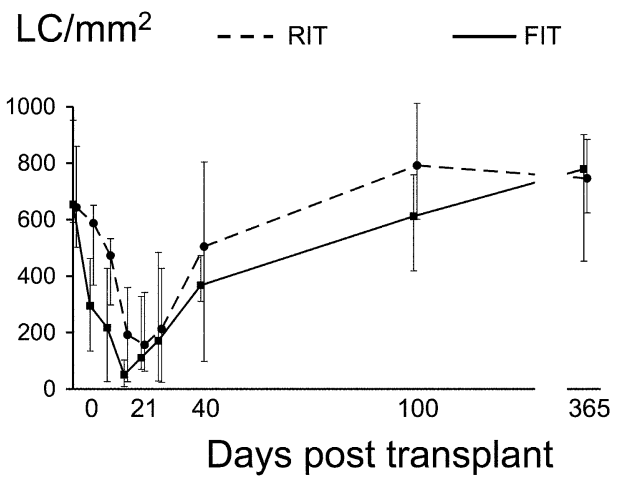

B

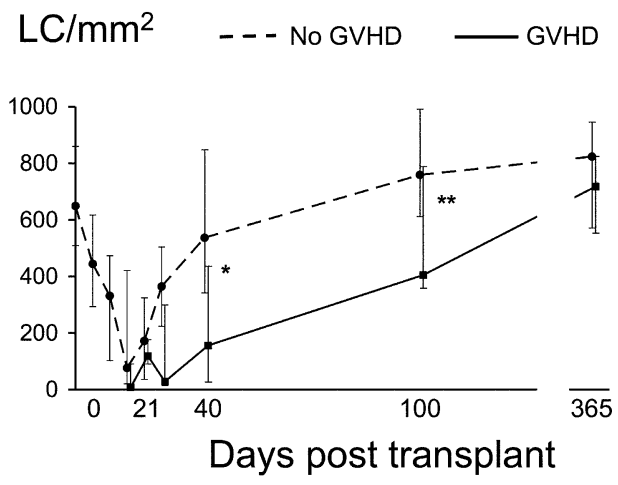

Figure 2. Recovery of LC after transplant and suppression by acute GVHD. (A) Comparison of conditioning therapy: solid line, FIT; dashed line, RIT. (B) Comparison of clinical cutaneous GVHD at time of biopsy: solid line, GVHD; dashed line, no GVHD. ${ }^{*}, P=0.018 ;{ }^{* *}, P=0.006$. The median \pm interquartile range is given, derived from 5 to 28 samples at each point. $x$ axis origin is $-7 d$ at the pretransplant time point.

that complete ablation of recipient APCs might abolish graft versus leukemia (GVL) effects (27), but a selective benefit might be gained by regional therapy of a GVHD target organ such as the skin.

\section{LC recovery and the effect of GVHD}

During recovery, LC density declined to a similar nadir during 14-21 $\mathrm{d}$ in both types of transplant (Fig. $2 \mathrm{~A}$ ). Although precise resolution of this phase is hampered by access to specimens, it suggests that the earlier difference between RIT and FIT seen at day 0 is partly kinetic (the response to RIT may be delayed with respect to FIT owing to the late scheduling of melphalan in RIT). Conditioning has a protracted effect throughout 14-21 d, suggesting that the tissue response to injury and dynamics of resident APC populations is relatively slow or that the absence of myeloid precursors during the hypoplastic phase further promotes LC depletion (24).

After $28 \mathrm{~d}$, there was no statistical difference between RIT and FIT patients; so, the data were reanalyzed according to cutaneous GVHD at the time of biopsy (Fig. 2 B). Patients without GVHD recovered pretransplant median LC density by $40 \mathrm{~d}\left(537 \mathrm{LC} / \mathrm{mm}^{2}\right.$ compared with $649 \mathrm{LC} / \mathrm{mm}^{2}$ pre- transplant; $\mathrm{P}=0.107)$, whereas those with GVHD remained significantly depressed at both $40 \mathrm{~d}\left(156 \mathrm{LC} / \mathrm{mm}^{2} ; \mathrm{P}=\right.$ $0.018)$ and $100 \mathrm{~d}\left(404 \mathrm{LC} / \mathrm{mm}^{2} ; \mathrm{P}=0.006\right)$. This suggests that the effect of conditioning, in which migration of one or more DC types primes the afferent arm of GVHD, is a distinct process to the depletion of LC that occurs later as a result of GVHD effector mechanisms or corticosteroid therapy. In earlier studies, the high rate of early acute GVHD or "engraftment syndrome" at days 14-21 may have obscured this distinction (11-14).

\section{Analysis of LC chimerism}

Congenic markers are not universally applicable to human transplants; therefore, genotype analysis must be used. In situ methods were avoided, following the observation that extensive activation of LC membrane occurs in the posttransplant period (Fig. 3 A). An alternate method of single cell genotyping was preferred in which cells migrating from epidermal sheets in vitro were subjected to two-step Giemsa/fluorescent in situ hybridization (FISH). The principal constituents of migratory cell preparations obtained in this way are keratinocytes and CD1a-positive LC with $<1 \% \mathrm{~T}$ cells or macrophages (Fig. 3 B). LC can be accurately identified by Giemsa staining alone (Fig. $3 \mathrm{C}$ ); this was confirmed in preparatory experiments by comparison with fluorescent CD1a or DR staining (not depicted). Approximately $20 \%$ of LC were recovered by migration. Although in vitro culture can exert selective effects, there is no a priori reason to suspect that either donor or recipient cells will be favored.

Many patients at $100 \mathrm{~d}$ after transplant had full donor LC chimerism as illustrated in Fig. 4 A. At $40 \mathrm{~d}$ after transplant, it was possible to detect mixtures of male and female cells as shown in Fig. 4 B. At 1 yr, a minority of patients had occasional recipient cells. Fig. $4 \mathrm{C}$ shows an example of 1 of 12 recipient cells detected in 1,746 interphase nuclei examined, a sensitivity of $<1 \%$ for recipient LC.

\section{LC engraftment}

A cohort of 32 patients (14 FIT and 18 RIT) was examined at $40 \mathrm{~d}, 100 \mathrm{~d}$, and 1 yr after transplant (Fig. 5 A). At $40 \mathrm{~d}$, the recovery after FIT was predominantly donor (median: 97\% donor; range: 89-100\%) compared with significant persistence of recipient cells after RIT (median: 36.5\% donor; range: $0-85 \% ; \mathrm{P}=0.004)$. However, by $100 \mathrm{~d}$, the majority of LC in all transplants were donor in origin with a median score of $100 \%$ (range: $93-100 \%$ ) after FIT and 97.5\% (range: 90-100\%) after RIT (P = 0.133). At 1 yr, both groups achieved median scores of 100\% (overall range: 97-100\%). Assuming recipient APCs are required to prime donor $\mathrm{T}$ cells for acute $\operatorname{GVHD}(2,5)$ and cellular GVL responses $(27)$, these events must occur within the first $100 \mathrm{~d}$ of fludarabine-mephalan RIT and probably within the first $40 \mathrm{~d}$ of conventional FIT.

The delay in donor engraftment of LC in RIT is in contrast with rapid blood myeloid engraftment in all transplants by day 30 (Fig. 5 B). As expected, there was a trend for higher 


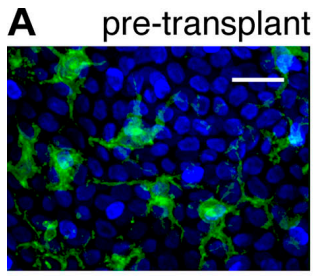

$100 \mathrm{~d}$

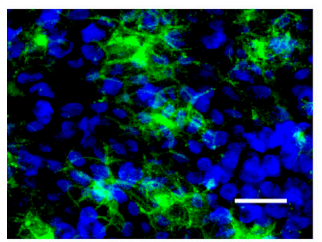

B

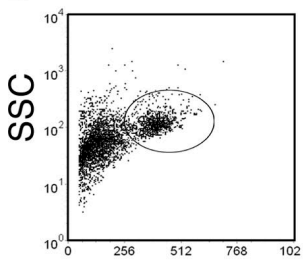

FSC

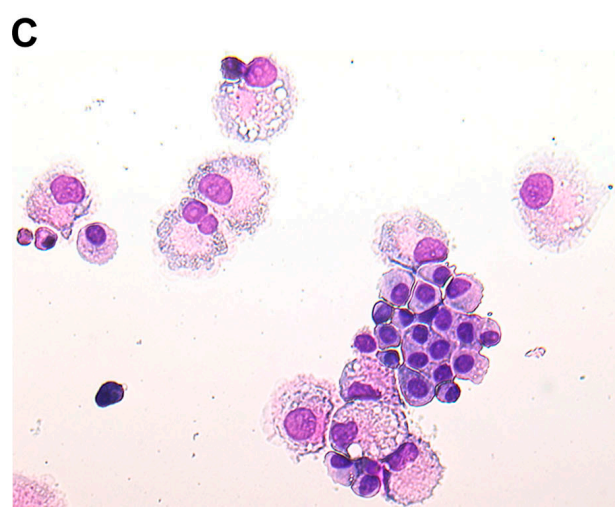

Figure 3. Isolation of LC by migration in vitro. (A) Morphological changes in LC during the course of transplantation illustrated using anti CD1a-FITC and DAPI counterstain. Bar, $20 \mu \mathrm{m}$. (B) Flow cytometry of migrant cells. LC are visible by scatter properties (left, oval region) and CD1a expression (right). $\mathrm{CD}^{+}$or $\mathrm{CD} 14^{+}$cells are $<1 \%$. The data are representative of 30 sex-matched transplants of whom 11 had active skin GVHD (clinical stages 1-2) at the time of biopsy. (C) Giemsa stain of epidermal migrants showing distinctive $\mathrm{LC}$ and keratinocyte morphology.

LC engraftment at day 100 in patients with complete myeloid chimerism $(\mathrm{P}=0.080$; Fig. $5 \mathrm{C}$ ). However, three patients with a delayed lapse of blood myeloid chimerism at 60-100 d (associated with declining $\mathrm{T}$ cell engraftment) did not suffer a similar reversal of LC engraftment, although none achieved $100 \%$ chimerism. This suggests there is a posttransplant window for LC engraftment (which may be regimendependent) beyond which LC are able to maintain relative independence from the blood myeloid compartment.
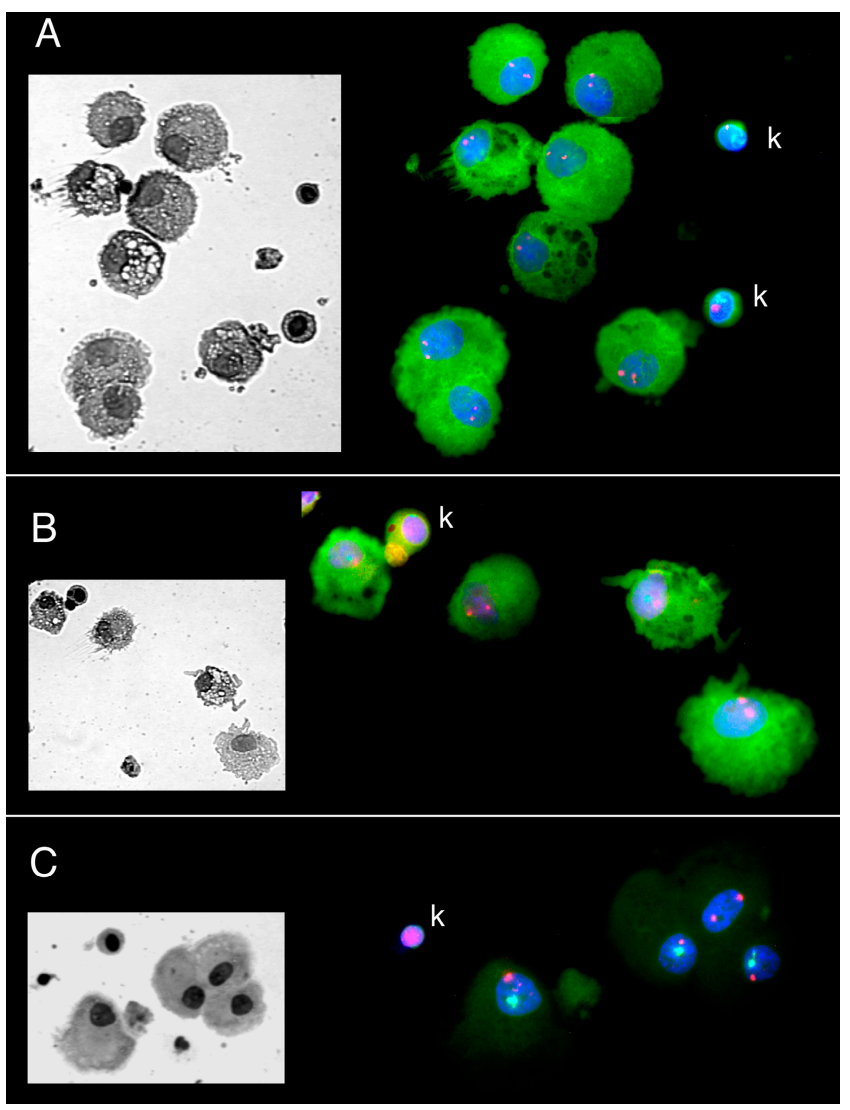

Figure 4. Single cell genotype analysis of LC. Paired Giemsa staining (left insets) and X/Y FISH (right: red X probe; green Y probe; blue DAPI counter stain). $k$, recipient keratinocyte. (A) Complete donor chimerism at day 100 in female to male transplant. (B) 50:50 mixed chimerism at day 40 in a female to male transplant. (C) A rare recipient cell at $1 \mathrm{yr}$, male to female transplant; lower autofluorescence in this experiment is the result of manual rather than automated Giemsa staining.

\section{The role of allogeneic $T$ cells}

Donor T cells promote LC engraftment in murine transplantation, under conditions of strict $\mathrm{T}$ cell depletion and MHC class II incompatibility (5). This effect was not evident in the human setting of in vivo $\mathrm{T}$ cell depletion and geno-identical transplant either in the whole cohort $(\mathrm{P}=0.759$; Fig. $5 \mathrm{C})$ or the RIT $(n=16)$ or sibling RIT subgroups $(n=12$; not depicted). However, a significant correlation between prior cutaneous GVHD and LC engraftment was observed $(\mathrm{P}=0.002$; Fig. 5 C). The induction of cutaneous GVHD, which was associated with donor $\mathrm{T}$ cell inoculum in the mouse, is a potential unifying mechanism for many variables that increase alloreactivity and enhance LC engraftment (5). Although we could not resolve a direct effect of donor $\mathrm{T}$ cells, the correlation of GVHD with donor chimerism confirms that alloreactivity is relevant to LC engraftment in humans. Two implications of this argument are that the priming phase of GVHD will be self-limiting and that the strategy of delayed $T$ cell add-back (28) will be compromised unless adjunctive treatment, such as UV light, is given to ensure complete LC chimerism (5). 


\section{Clinical outcomes}

Our results show that transplant regimens in clinical use promote high levels of LC engraftment by day 100 . There was no difference in event-free survival between patients who achieved $100 \%$ donor chimerism and those who did not, supporting the concept that GVHD and GVL are distinct but overlapping processes (Fig. S1, available at http://www.jem. org/cgi/content/full/jem.20051787/DC1). RIT patients have lower LC donor chimerism at day 40, but often first experience acute GVHD between 60-100 d during immunosuppression withdrawal. We have argued that GVHD or alloreactivity is important in promoting LC engraftment and predict that this is increasingly important as the intensity of conditioning is reduced. To test this, it would be informative to examine LC chimerism in minimal conditioning RIT regimens (29) in which acute GVHD manifestations are even further retarded (19).

The observation of high donor chimerism at $100 \mathrm{~d}$ is consistent with the hypothesis that the transition of acute to chronic GVHD at $100 \mathrm{~d}$ is related to indirect antigen presentation by donor APCs $(22,23)$. However, it now seems unlikely that the increased toxicity of early DLI is related to persistence of recipient APC $(20,21)$, unless cells that have migrated have extended longevity in lymphoid tissue. An alternative explanation worthy of consideration is that active tolerance mechanisms evolve to render DLI increasingly safe with time.

\section{MATERIALS AND METHODS}

Patients and biopsies. Consecutive patients who gave consent for study between April 2003 and June 2005 were recruited from four centers in the United Kingdom: Newcastle; Leeds; Christie Hospital, Manchester; and The Royal Free Hospital, London. 4-5-mm skin biopsies were performed at routine day 100 bone marrow aspiration from the posterior iliac crest. Additional 2- or 4-mm biopsies from the posterior iliac crest were obtained from patients transplanted at Newcastle at varying intervals. 184 skin biopsies were obtained from 76 patients. 48 patients received RIT, the majority with fludarabine, melphalan, and alemtuzumab (35) or fludarabine and melphalan (12). 28 patients received FIT, the majority with a total body irradiation regimen (16) or busulfan and cyclophosphamide (11) with or without alemtuzumab. All unrelated transplants, either RIT or FIT, received a regimen containing alemtuzumab. There were 44 HLA-identical siblings and 32 HLA-matched unrelated donors. GVHD prophylaxis consisted of pulsed methotrexate and cyclosporine or cyclosporine alone if a patient had received alemtuzumab. All patients were in remission or first chronic phase at transplantation. The median interval between prior therapy and transplant was 3 mo (range: $1-10 \mathrm{mo}$ ); three patients treated within 3 mo of transplant had received systemic corticosteroids. Full details of the patients used for LC chimerism analysis are included in Table S1 (available at http://www.jem.org/cgi/content/full/jem.20051787/DC1). Normal control skin was obtained from patients undergoing plastic surgery. All procedures were performed with informed consent and ethical approval obtained from Newcastle and North Tyneside Local Research Ethics Committee, Leeds Health Authority Local Research Ethics Committee, South Manchester Local Research Ethics Committee, and Royal Free Hospital and Medical School Ethics Committee. Clinical chimerism analysis on bone marrow, whole blood, myeloid $\left(\mathrm{CD}^{+} 5^{+}\right)$, and $\mathrm{T}$ cell $\left(\mathrm{CD}^{+}\right)$fractions was performed according to local protocols using magnetic bead fractionation and X/Y FISH or PCR of short tandem repeats. GVHD was assessed clinically at the time of biopsy or from case notes. Cutaneous GVHD stages 1-2 was treated with topical betamethasone valerate $0.122 \%$; cutaneous
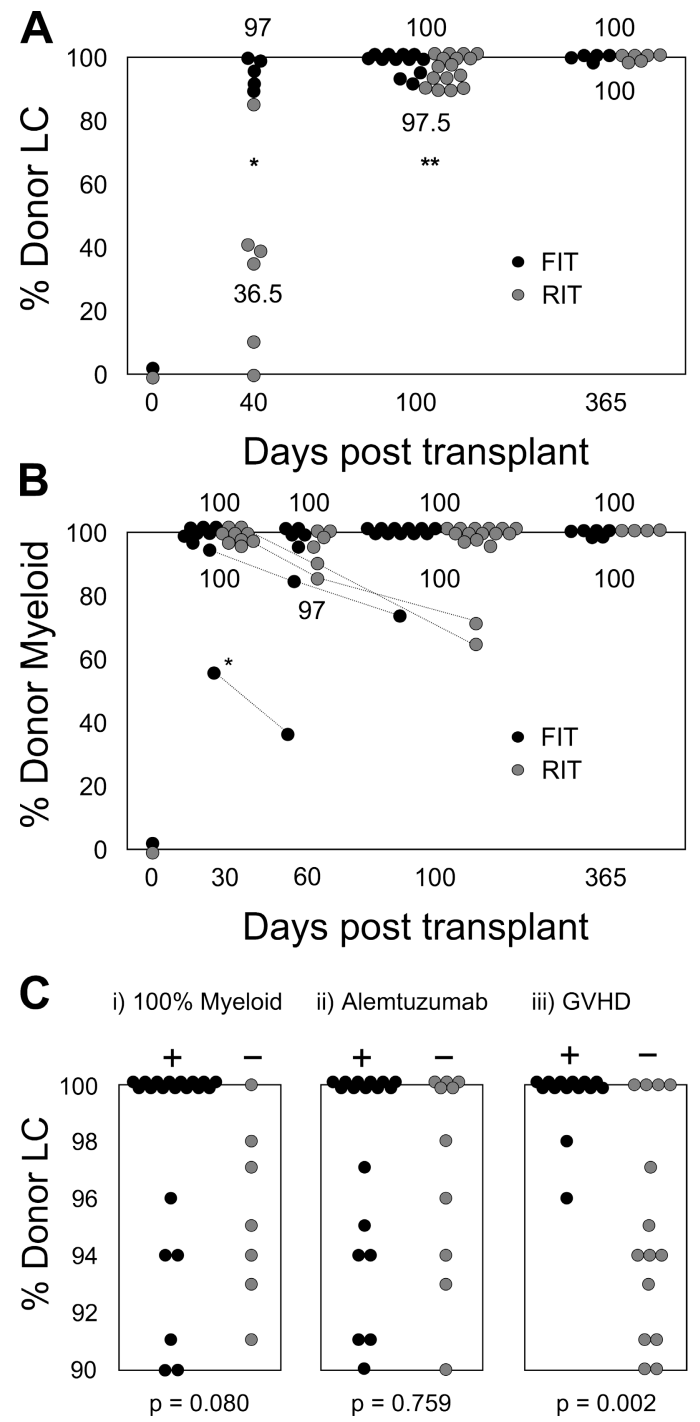

Figure 5. Donor chimerism of LC. (A) LC chimerism at 40,100, and $365 \mathrm{~d}$ after transplant for patients receiving FIT (black circles) and RIT (gray circles). The median percentage is depicted above the data for FIT and below the data for RIT. ${ }^{*} \mathrm{P}=0.004{ }^{*}{ }^{*}, \mathrm{P}=0.133$, comparing RIT with FIT. (B) Blood myeloid chimerism at 30,60, 100, and $365 \mathrm{~d}$ after transplant for patients receiving FIT (black circles) and RIT (gray circles). Broken lines connect samples from the same patient. The median percentage is depicted above the data for FIT and below the data for RIT. ${ }^{*}$, early relapse of chronic myeloid leukemia. (C) Distribution of LC chimerism at day 100 according to: (i) complete myeloid engraftment; (ii) alemtuzumab conditioning (T cell depletion); and (iii) prior acute cutaneous GVHD.

GVHD stages 3-4 or any acute GVHD grades II-IV was treated initially with $2 \mathrm{mg} / \mathrm{kg}$ intravenous methylprednisone and then oral prednisone $1 \mathrm{mg} / \mathrm{kg}$ tapered according to response.

Immunofluoresence microscopy. Skin was trimmed of excess dermis and incubated at $37^{\circ} \mathrm{C}$ for $60-90 \mathrm{~min}$ in RPMI 1640 (Invitrogen) with $1 \mathrm{mg} / \mathrm{ml}$ dispase (Invitrogen). Epidermal sheets were separated, fixed in acetone for $15 \mathrm{~min}$, and rehydrated in PBS (Cambrex) for $15 \mathrm{~min}$. Anti-CD1a monoclonal NA 1/34 (DakoCytomation) was used at 1/10 dilution for $2 \mathrm{~h}$ at room temperature or overnight at $4^{\circ} \mathrm{C}$. Specimens were mounted in 
VectaStain containing DAPI (Vector Laboratories) and analyzed with a Leica TCS SP2 UV confocal microscope and LCS V 2.51 imaging software (Leica). Typically, 12-16 images were acquired over $20-30-\mu \mathrm{m}$ depth at pixel resolution $1025 \times 1025,40 \times$ power, pinhole $1.5-1.8$, and voltage offset 350-500 V. In most samples, counts were the mean of two $40 \times$ fields selected at random in the interfollicular epidermis (total area: $750 \mu \mathrm{m}^{2}$ ).

Chimerism analysis. LC were allowed to migrate from 4-mm punch epidermal sheets by floatation on $400 \mu \mathrm{l}$ of X-Vivo 10 medium (Biowhittaker) supplemented with $500 \mathrm{IU} / \mathrm{ml} \mathrm{GM-CSF}$ (Peprotech) in a 48-well culture plate (Nunc) incubated at $37^{\circ} \mathrm{C}$ for $60 \mathrm{~h}$. In sex-mismatched transplants, migrant cells were harvested onto cytospin slides at 800 revolutions/min for $4 \mathrm{~min}$ (Thermo Shandon) for FISH. Migratory cells from sex-matched transplants were analyzed by flow cytometry as described previously (25). Approximately 1,000 cells were obtained from most biopsies; examination of the epidermal sheet after migration revealed none remaining. Cytospin slides were air-dried and either stained immediately with an automated stainer (brighter autofluorescence but weaker FISH) before storage at $-20^{\circ} \mathrm{C}$ or stored first and stained manually after thawing with Leishman and Giemsa stains 10:1 (BDH) for $5 \mathrm{~min}$ at room temperature (less autofluoresence but better FISH). About $20 \times 20$ Giemsa-stained fields (100-300 LC) were located captured and annotated using Applied Imaging Cytovision software. Slides fixed for FISH in methanol/acetic acid 3:1 for 5 min, probed with CEP X/Y DNA probes (Vysis) according to manufacturer's instructions and mounted with VectaStain containing DAPI (Vector Laboratories). Giemsastained fields were reexamined and LC genotype scored. FISH images were recorded using Applied Imaging Smartcapture software.

Data analysis. Mann-Whitney tests were run on SPSS 12. Images were processed with Adobe Photoshop 7.0. Cytogenetic images were captured at high power and assembled as montages of several fields for clarity of comparison with Giemsa images. Square cropping and normalizing the background were the only image adjustments made.

Online supplemental material. Table S1 contains patient characteristics. Fig. S1 shows event-free survival according to LC engraftment. Online supplemental material is available at http://www.jem.org/cgi/content/full/jem. 20051787/DC1.

We gratefully acknowledge the generosity and assistance of our patients and transplant coordinators: C. Richardson; M. Elliott (Newcastle); D. Buchanan (Leeds); J. Coombes (Manchester); and B. Leung (London). We also thank N. Bown (Northern Genetics Service); T. Booth (Bioimaging Services); and the RVI Plastic Surgery Department (Newcastle).

This work was supported by the Leukemia Research Fund, UK grant no. 0169, the European Commission grant "TRANSEUROPE" OLK3-CT-2002-01936, and the Tyneside Leukemia Research Association.

The authors have no conflicting interests.

\section{Submitted: 2 September 2005}

Accepted: 1 December 2005

\section{REFERENCES}

1. Ferrara, J.L., K.R. Cooke, and T. Teshima. 2003. The pathophysiology of acute graft-versus-host disease. Int. J. Hematol. 78:181-187.

2. Shlomchik, W.D., M.S. Couzens, C.B. Tang, J. McNiff, M.E. Robert, J. Liu, M.J. Shlomchik, and S.G. Emerson. 1999. Prevention of graft versus host disease by inactivation of host antigen-presenting cells. Science. 285:412-415.

3. Matte, C.C., J. Liu, J. Cormier, B.E. Anderson, I. Athanasiadis, D. Jain, J. McNiff, and W.D. Shlomchik. 2004. Donor APCs are required for maximal GVHD but not for GVL. Nat. Med. 10:987-992.

4. Anderson, B.E., J.M. McNiff, D. Jain, B.R. Blazar, W.D. Shlomchik, and M.J. Shlomchik. 2005. Distinct roles for donor- and host-derived antigen-presenting cells and costimulatory molecules in murine chronic graft-versus-host disease: requirements depend on target organ. Blood. 105:2227-2234.
5. Merad, M., P. Hoffmann, E. Ranheim, S. Slaymaker, M.G. Manz, S.A. Lira, I. Charo, D.N. Cook, I.L. Weissman, S. Strober, and E.G. Engleman. 2004. Depletion of host Langerhans cells before transplantation of donor alloreactive $\mathrm{T}$ cells prevents skin graft-versus-host disease. Nat. Med. 10:510-517.

6. Tamaki, K., G. Stingl, and S.I. Katz. 1980. The origin of Langerhans cells. J. Invest. Dermatol. 74:309-311.

7. Merad, M., M.G. Manz, H. Karsunky, A. Wagers, W. Peters, I. Charo, I.L. Weissman, J.G. Cyster, and E.G. Engleman. 2002. Langerhans cells renew in the skin throughout life under steady-state conditions. Nat. Immunol. 3:1135-1141.

8. Fearnley, D.B., L.F. Whyte, S.A. Carnoutsos, A.H. Cook, and D.N. Hart. 1999. Monitoring human blood dendritic cell numbers in normal individuals and in stem cell transplantation. Blood. 93:728-736.

9. Klangsinsirikul, P., G.I. Carter, J.L. Byrne, G. Hale, and N.H. Russell. 2002. Campath-1G causes rapid depletion of circulating host dendritic cells (DCs) before allogeneic transplantation but does not delay donor DC reconstitution. Blood. 99:2586-2591.

10. Auffermann-Gretzinger, S., I.S. Lossos, T.A. Vayntrub, W. Leong, F.C. Grumet, K.G. Blume, K.E. Stockerl-Goldstein, R. Levy, and J.A Shizuru. 2002. Rapid establishment of dendritic cell chimerism in allogeneic hematopoietic cell transplant recipients. Blood. 99:1442-1448.

11. Perreault, C., M. Pelletier, D. Landry, and M. Gyger. 1984. Study of Langerhans cells after allogeneic bone marrow transplantation. Blood. 63 : 807-811.

12. Sloane, J.P., J.A. Thomas, S.F. Imrie, D.F. Easton, and R.L. Powles, 1984. Morphological and immunohistological changes in the skin in allogeneic bone marrow recipients. J. Clin. Pathol. 37:919-930.

13. Murphy, G.F., Y. Merot, A.K. Tong, B. Smith, and M.C. Mihm Jr. 1985. Depletion and repopulation of epidermal dendritic cells after allogeneic bone marrow transplantation in humans. J. Invest. Dermatol. 84 210-214.

14. Atkinson, K., V. Munro, E. Vasak, and J. Biggs. 1986. Mononuclear cell subpopulations in the skin defined by monoclonal antibodies after HLAidentical sibling marrow transplantation. Br. J. Dermatol. 114:145-160.

15. Volc-Platzer, B., G. Stingl, K. Wolff, W. Hinterberg, and W. Schnedl. 1984. Cytogenetic identification of allogeneic epidermal Langerhans cells in a bone-marrow-graft recipient. N. Engl. J. Med. 310:1123-1124.

16. Perreault, C., M. Pelletier, R. Belanger, J. Boileau, Y. Bonny, M. David, M. Gyger, D. Landry, and S. Montplaisir. 1985. Persistence of host Langerhans cells following allogeneic bone marrow transplantation: possible relationship with acute graft-versus-host disease. Br. J. Haematol. 60:253-260.

17. Czernielewski, J.M., and M. Demarchez. 1987. Further evidence for the self-reproducing capacity of Langerhans cells in human skin. J. Invest. Dermatol. 88:17-20.

18. Kanitakis, J., P. Petruzzo, and J.M. Dubernard. 2004. Turnover of epidermal Langerhans' cells. N. Engl. J. Med. 351:2661-2662.

19. Mielcarek, M., P.J. Martin, W. Leisenring, M.E. Flowers, D.G. Maloney, B.M. Sandmaier, M.B. Maris, and R. Storb. 2003. Graftversus-host disease after nonmyeloablative versus conventional hematopoietic stem cell transplantation. Blood. 102:756-762.

20. Marks, D.I., R. Lush, J. Cavenagh, D.W. Milligan, S. Schey, A. Parker, F.J. Clark, L. Hunt, J. Yin, S. Fuller, et al. 2002. The toxicity and efficacy of donor lymphocyte infusions given after reduced-intensity conditioning allogeneic stem cell transplantation. Blood. 100:3108-3114.

21. Peggs, K.S., K. Thomson, D.P. Hart, J. Geary, E.C. Morris, K. Yong, A.H. Goldstone, D.C. Linch, and S. Mackinnon. 2004. Dose-escalated donor lymphocyte infusions following reduced intensity transplantation: toxicity, chimerism, and disease responses. Blood. 103:1548-1556.

22. Shlomchik, W.D. 2003. Antigen presentation in graft-vs-host disease. Exp. Hematol. 31:1187-1197.

23. Merad, M. 2005. Ontogeny of Langerhans cells and graft versus host disease. Adv. Exp. Med. Biol. 560:115-123.

24. Ratzinger, G., J.L. Reagan, G. Heller, K.J. Busam, and J.W. Young. 2003. Differential CD52 expression by distinct myeloid dendritic cell subsets: implications for alemtuzumab activity at the level of antigen presentation in allogeneic graft-host interactions in transplantation. Blood. 101:1422-1429. 
25. Collin, M.P., D. Munster, G. Clark, X.N. Wang, A.M. Dickinson, and D.N. Hart. 2005. In vitro depletion of tissue-derived dendritic cells by CMRF-44 antibody and alemtuzumab: implications for the control of Graft-versus-host disease. Transplantation. 79:722-725.

26. Perez-Simon, J.A., P.D. Kottaridis, R. Martino, C. Craddock, D. Caballero, R. Chopra, J. Garcia-Conde, D.W. Milligan, S. Schey, A. Urbano-Ispizua, et al. 2002. Nonmyeloablative transplantation with or without alemtuzumab: comparison between 2 prospective studies in patients with lymphoproliferative disorders. Blood. 100:3121-3127.

27. Mapara, M.Y., Y.M. Kim, S.P. Wang, R. Bronson, D.H. Sachs, and M. Sykes. 2002. Donor lymphocyte infusions mediate superior graftversus-leukemia effects in mixed compared to fully allogeneic chi- meras: a critical role for host antigen-presenting cells. Blood. 100: 1903-1909.

28. Barrett, A.J., D. Mavroudis, J. Tisdale, J. Molldrem, E. Clave, C. Dunbar, M. Cottler-Fox, S. Phang, C. Carter, P. Okunnieff, et al. 1998. T cell-depleted bone marrow transplantation and delayed $\mathrm{T}$ cell add-back to control acute GVHD and conserve a graft-versus-leukemia effect. Bone Marrow Transplant. 21:543-551.

29. Baron, F., J.E. Baker, R. Storb, T.A. Gooley, B.M. Sandmaier, M.B. Maris, D.G. Maloney, S. Heimfeld, D. Oparin, E. Zellmer, et al. 2004 Kinetics of engraftment in patients with hematologic malignancies given allogeneic hematopoietic cell transplantation after nonmyeloablative conditioning. Blood. 104:2254-2262. 